\title{
Line Balancing of Sewing Systems
}

\section{(A Simple Calculating Method to Determine the Number of Workstations and Cycle Time)}

\author{
By Masaru Nakajima,* Sei Uchiyama,* and Yoshito Miura*, Members TMSJ \\ Katsuyuki Sakamoto** and Yukihiro Ando** \\ *Department of Textile Systems Engineering, Kyoto University of Industrial Arts \\ and Textile Fibers, Matsugasaki, Sakyo-ku, Kyoto-shi, 606 Japan \\ **Industrial Sewing Machine Section, Aishin Seiki Co., Ltd., Asahi-cho, Kariya-shi, 448 Japan
}

Based on the Journal of the Textile Machinery Society of Japan, Transactions, Vol. 33, No. 4, T22-28 (1980)

\begin{abstract}
A simple calculating method is proposed to determine the number of workstations and the cycle tim by introducing a new concept of unbalanced time, aiming at high productivity and labour saving.

The utility and feasibility of this method is discussed by applying to a practical sewing system. The results are as follows:

(1) Applying this method to the number of workstations, the number of workers was able to decrease from 8 to 7 under the same production quantity.

(2) Applying this method to the cycle time, the production quantity was increased to 78 from 63 clothes/8hr./worker).

(3) It is concluded that this simple calculating method is applicable to a practical sewing system.
\end{abstract}

\section{Introduction}

The sewing-process of clothes is an assembly process in which components of clothes are sewn with the machine. It belongs to a flow type process, and to a man-machine system of multistages. Recently, the rapid progress of speed up and automation labour saving and productivity improvement are remarkable in sewing. But, from the view point of managerial technique, the production management such as production planning, process planning, process design, operation design of the sewing system has almost been performed by intuition and experience ${ }^{[1]}$.

So, from the point of the line balancing of processes, the optimum calculating method of the workstation number, already proposed by Jackson ${ }^{[2]}$, and the minimum calculating procedure of the cycle time are studied by using the concept of "unbalanced time". These calculating methods are then applied to a sewing process in practical clothes making (geans), to examine the utility and usefulness of these method.

\section{Theory}

\subsection{Symbols}

The following symbols are defined:
$E$ : efficiency of process formation

$H$ : planned production period

$K$ : number of elemental works (the work by a single machine is an elemental work)

$k$ : number of workstations

$M_{i, j}: j$-th machine in $i$-th workstation

$N$ : number of workstations (the machine block that one worker takes part is one workstation. So, " $N$ " is the total workers)

$N^{*}$ : optimal number of workstations

$N_{\text {reas }}$ : practical number of workstations

$N_{\text {max }}$ : theoretical maximum of the number of workstations

$N_{\text {min }}$ : theoretical minimum of the number of workstations

$P_{\max }$ : maximum among sum totals of elemental working times per each workstation after the process is designed

$Q$ : quantity of planned productions

$S_{k}$ : set of elemental works that are assigned to the k-th workstation

$T$ : total sewing time (the total elemental working time $=\sum_{i=1}^{k} t_{i}$

$t_{i}$ : working time of the $i$-th elemental work $(i=1,2, \ldots, K)$ including the time for attaching, sewing and detaching of parts 
$\sum_{i \in s_{k}} t_{i}$ : total working time of elemental works of the $k$-th workstation

$x$ : coefficient for the excess cycle time

\lrcorner : total idle and excess time (the total unbalanced time)

$\delta_{k}$ : unbalance time of the $k$-th workstation

$\tau$ : cycle time (the standard time selected from several total elemental working times per each workstation)

$\tau_{m}$ : perfectly balanced cycle time

$\tau$ theo $:$ rough cycle time

\subsection{Schema of sewing system}

The sewing system in this study is shown in Fig. 1. One worker is arranged at each workstation, and takes part in operating more than one machine. The process sequence is shown by arrows in the figure. Each work at the machine is done along the flow direction indicated by the broken line, and returned back to the first machine after it is completed.

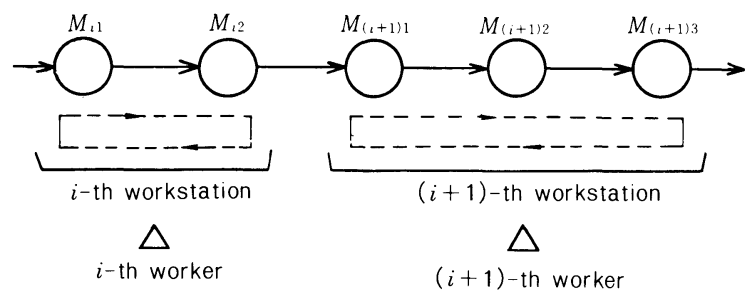

Fig. I Sewing system.

\subsection{Basic concept of line balancing}

$\mathrm{K}$. Hitomi ${ }^{[3]}$ defines that the line balancing is to decide optimal values for the following items:

1. cycle time

2. group formation of elemental works (assigning the elemental works of undividable minimum unit to the same process (workstation) so as not to disturb the feasible technical production sequence

3. number of workstations

In line balancing, such quantities must be known beforehand as the basic data in production, the kind and quantity of products, the sequence of elements in work, the working time, and the construction of sewing process. The problem to be solved is as follows:

(1) Determing the optimum (minimum) number of workstations for a fixed cycle time.

(2) Minimizing the cycle time for the fixed workstation. In this case, our objective is to maximize the production at the fixed workers. In either case, the total idle and excess time becomes the minimum as

$$
\Delta=\sum_{i=1}^{N}\left|\tau-\sum_{i \in s_{k}} t_{i}\right|
$$

(3) Trying to maximize the formation efficiency $E$ given below, and deciding the cycle time and the number of the workstations. In this case, our objective is the maximum economical efficiency.

$$
E=\frac{T}{N \tau}
$$

2.4 Procedure for deciding the optimum value of workstations

The optimum value of workstations is given by such work formation as satisfying the constraints of technical sequence of elemental works and minimizing the difference between the fixed cycle time and the total elemental work time assigned to each workstation. Therefore, we must minimize the idle and excess time $J$ shown below:

$$
\Delta=\sum_{k=1}^{N}\left|\tau-\sum_{i \in S_{k}} t_{i}\right|
$$

Here, if

$$
\delta_{k}=\tau-\sum_{i \in s_{k}} t_{i}
$$

then

$$
\Delta=\sum_{k=1}^{N}\left|\delta_{k}\right|
$$

where $\Delta$ is "unbalance time".

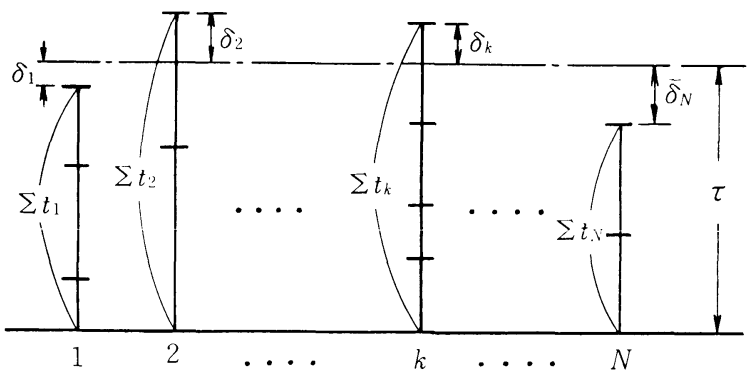

Fig. 2 Relation between unbalanced time $i_{k}$ and cycle time :

The relation between $i_{k}$ and the cycle time - is represented in Fig. 2. When the formation is organized by grouping elemental works, the workstation which exceeds the cycle time - appears. The excess time from this cycle time is defined to be about $5-10 \%$ of $\tau$. By such allowable excess time, the degree of freedom for the formation combination increases and the $\Delta$ in equ. 1 decreases as compared with the former method by which the total idle time is minimized under the condition that the total elemental working time arranged to each workstation does't exceed the fixed cycle time.

Secondly, the theoretical minimum of workstations $\left(N_{\min }\right)$ is given by

$$
\begin{aligned}
N_{\min } & =\min \left\{\text { in teger } N \mid N \geq \sum_{i=1}^{K} t_{i} / \tau\right\} \\
& =\left[\frac{T}{\tau}\right]+1 \ldots \ldots \ldots \ldots \ldots \ldots \ldots \ldots \ldots \ldots \ldots \ldots \ldots \ldots \ldots
\end{aligned}
$$

where [T/:] is Gauss symbol and is equal to $T / \tau$ or is the maximum integer not larger than $T / \tau$. 
The theoretical maximum is

$$
N_{\max }=K
$$

As the practicable minimum of workstations $\left(N_{\mathrm{fens}}\right)$ is less than the number of elemental works that have larger working time than $\alpha_{*} / 2$, it is

$$
N_{\text {feas }}=\left\{N(i) \mid t_{i}>\frac{\alpha \tau}{2}\right\}
$$

where $N(i)$ means the number of $i$. Therefore, the optimum value of workstations $\left(N^{*}\right)$ is in the following range:

$$
\max \left(N_{\min }, N_{\text {feas }}\right) \leq N^{*} \leq N_{\text {max }}
$$

To minimize the workstation number, the following must be satisfied:

$$
\max \left(N_{m i n}, N_{\text {feas }}\right)=N^{*}
$$

\subsection{Procedure for deciding the minimal cycle time}

Deciding the minimal cycle time is effective to increase the production per unit time. From the order specification, such data are known as technical process sequence, the working time for each element work the planned production period $[H(\mathrm{~h})]$, and the planned quantity of production $[Q$ (unit)]. We discuss the line balancing under the above mentioned conditions to minimize the total unbalanced time $J$. In the case that the workstation number is fixed, we may minimize the cycle time, which is the maximum of the total elemental working time $\boldsymbol{P}_{\max }$ in the workstation.

For minimizing the total unbalanced time $\Delta$, the total sewing time must be equal to the product of workstation number $N$ and the cycle time $(J=0)$. But as this case is rare, we try to minimize $J$ of eq. (3). So, first we take the rough cycle time by

$$
\tau_{\text {theo }}=\frac{H}{Q}
$$

Secondly, the minimal workstation number is decided by equ. (4), and the perfectly balanced time is given by

$$
\tau_{m}=\frac{T}{N_{m i n}}
$$

If, $\tau_{\text {llion }} \leq \tau_{m}$, we repeat the calculation to minimize the total of

$$
\delta_{k}=-\tau \cdots \sum_{i=s_{k}} t_{i}
$$

\section{Applying to the actual sewing system}

3.1 Deciding the optimum workstation number

By applying the theory of line balancing to the actual sewing system, the utility is examined. Let us suppose the case that the workman geans are sewn under the conditions of Table 1 and Fig. 3. In Fig. 3, the number shows the pro- cess sequence and is equivalent to the number in Table 1. The name of work and the sum of time (processing time) required for attaching, sewing, and detaching are shown in Table 2. The measurement time was done with a stopwatch, and is the mean for about an hour and eight workers.

From the data and eq. (5), the theoretical maximum of workstations is

$$
N_{\max }=15
$$

Secondly, from eq. (4) the theoretical minimum of workstations is

$$
\begin{aligned}
N_{\min } & =\left[\frac{T}{\tau}\right]+1 \\
& =\left[\frac{354.9}{57.0}\right]+1=7
\end{aligned}
$$

The practicable minimum of workstations is from eq. (6), as $\_=1.025$,

$$
N_{\text {feas }}=\left\{N(i) \mid t_{i}>29.2\right\}=4
$$

So, the range of the optimum workstation number is, from eq. (7),

$$
7 \leqq N^{*} \leqq 15
$$

As the minimum of workstation number is the minimal workmen of the system, the following formation is tried with $N^{*}=7$.

First, the sequence of processes satisfying the technical constraints is shown by the arrows in Fig. 4. Next, it is an
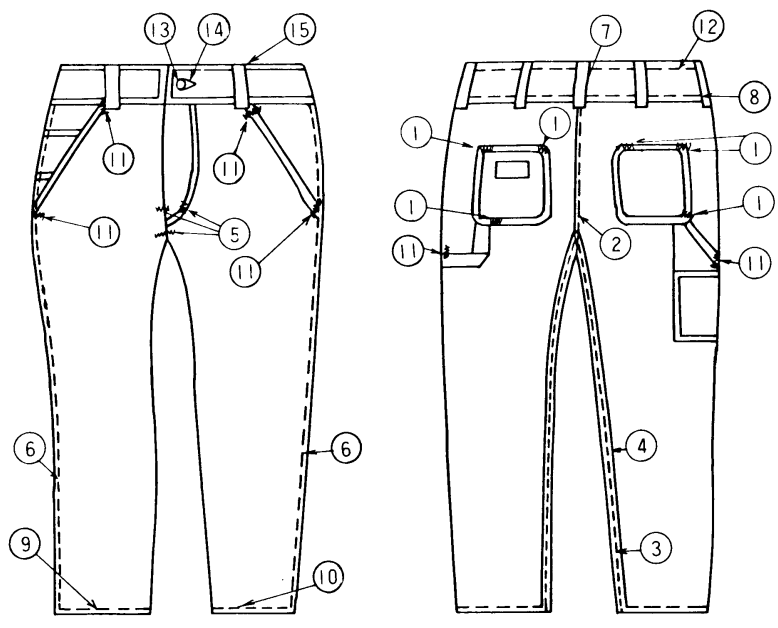

(Twill 800 or 10-120 Z Denims. Numbers show the process sequence).

Fig. 3 Sewn points of workman jeans.

important problem how to set the cycle time - . If the maximum of the station times $\left(\boldsymbol{P}_{\max }\right)$ is enough to meet the production, this maximum is set as the cycle time - . In this case, 
Table 1 Sewing conditions

\begin{tabular}{|c|c|c|c|c|}
\hline Sequence & Work name & Seam type & Seam number & $\begin{array}{l}\text { Sewn length } \\
(\mathrm{mm})\end{array}$ \\
\hline 1 & Bar-tacks & Lock-stitch & 24 & 12 \\
\hline 2 & Butted seams on the groin & $\begin{array}{l}\text { Double chain stitch } \\
\text { ( } 3 \text { needles, } 4 \text { yarns) }\end{array}$ & 150 & 450 \\
\hline 3 & Butted seams under the groin & $\begin{array}{l}\text { Double chain stitch } \\
\text { \& seam }\end{array}$ & 840 & 1680 \\
\hline 4 & Stitch under the groin & Double chain stitch & 560 & 1680 \\
\hline 5 & Bar-tacks & Lock-stitch & $\begin{array}{c}24 \\
\text { (per one place) }\end{array}$ & 12 \\
\hline 6 & Side seam (right and left) & $\begin{array}{l}\text { Double chain stitch } \\
\text { ( } 3 \text { needles, } 4 \text { yarns) }\end{array}$ & $364 \times 2$ & $1090 \times 2$ \\
\hline 7 & Labelling & Lock-stitch & 20 & 60 \\
\hline 8 & Belt seam & Double chain stitch & 274 & 820 \\
\hline 9 & Bottom seam (left) & Double chain stitch & 154 & 460 \\
\hline 10 & Bottom seam (right) & Double chain stitch & 154 & 460 \\
\hline 11 & Bar-tacks & Lock-stitch & $\begin{array}{c}24 \\
\text { (per one place) }\end{array}$ & 12 \\
\hline 12 & Belt stitch & Lock-stitch & 264 & 790 \\
\hline 13 & Button Calking & & & \\
\hline 14 & Linking of eyelet hole & Double chain stitch & 50 & 54 \\
\hline 15 & Band looping & Lock-stitch & $\begin{array}{c}18 \\
\text { (per one place) }\end{array}$ & 12 \\
\hline
\end{tabular}

Remark: Button calking (13) is carried by a press machine

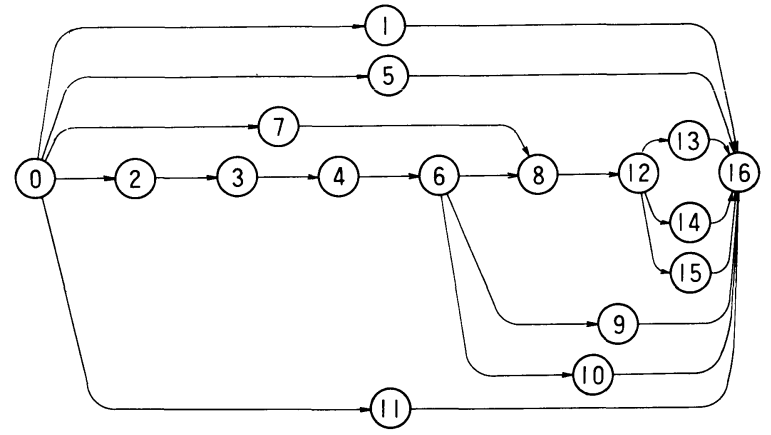

Fig. 4 Technically feasible sequence of sewing process and show start and end.

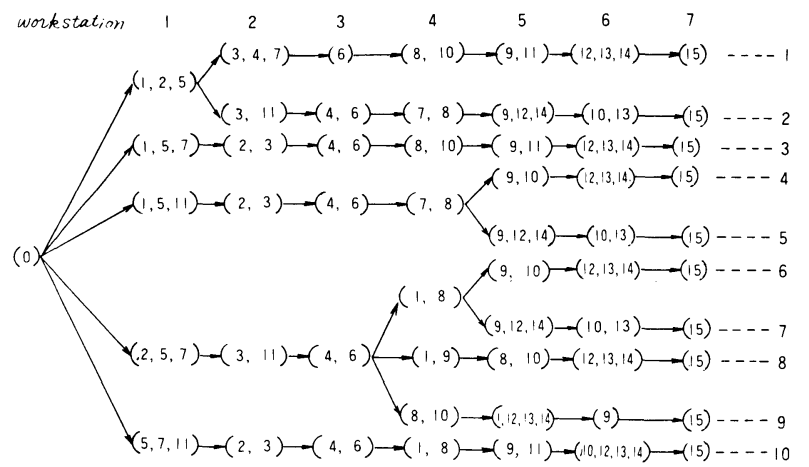

Fig. 5 Process formation when $N=7$ by Jackson's enumeration method.
Table 2 Processing time

\begin{tabular}{clc}
\hline Sequence & Work name & Processing time (sec) \\
\hline 1 & Bar-tacks & 15.0 \\
2 & Butted seams on the groin & 31.5 \\
3 & Butted seams under the groin & 23.0 \\
4 & Stitch under the groin & 16.3 \\
5 & Bar-tacks & 10.5 \\
6 & Side seam (right and left) & 40.6 \\
7 & Labelling & 14.9 \\
8 & Belt seam & 36.6 \\
9 & Bottom seam (left) & 26.4 \\
10 & Bottom seam (right) & 16.9 \\
11 & Bar-tacks & 29.0 \\
12 & Belt stitch & 23.4 \\
13 & Button calking & 7.8 \\
14 & Linking of eyelet hole & 6.0 \\
15 & Band looping & 57.0 \\
\hline
\end{tabular}

to decrease the workstation number decreases the workmen, and gives $P_{\max }=57.0 \mathrm{sec}$. If the given production is obtained ( 505 clothes/day) by this value, the process formation is done to minimize the total unbalanced time $J$ by substituting this $P_{\text {max }}$ to $\tau$ in eq. 2 .

The ten process formations in Fig. 5 are given for $N=7$ under the conditions of Fig. 4. All these combinations give the unbalanced time of $44.1 \mathrm{sec}$. The selecting method depends upon the decision making of the production manager. If the process resembling the existing formation is adpoted, 
it becomes No. 1, namely $(1,2,5)-(3,4,7)-(6)-(8,10)$ $(9,11)-(12,13,14)-(15)$, the relation between various factors of which is shown in Fig. 6, that indicates there is no process exceeding $\tau=57.0$. So, the unbalanced time $J$ is the total of the idle time, and the decrease to seven workers from eight without changing the production is realized. The formation efficiency of process $E$ is $0.89(89 \%)$.

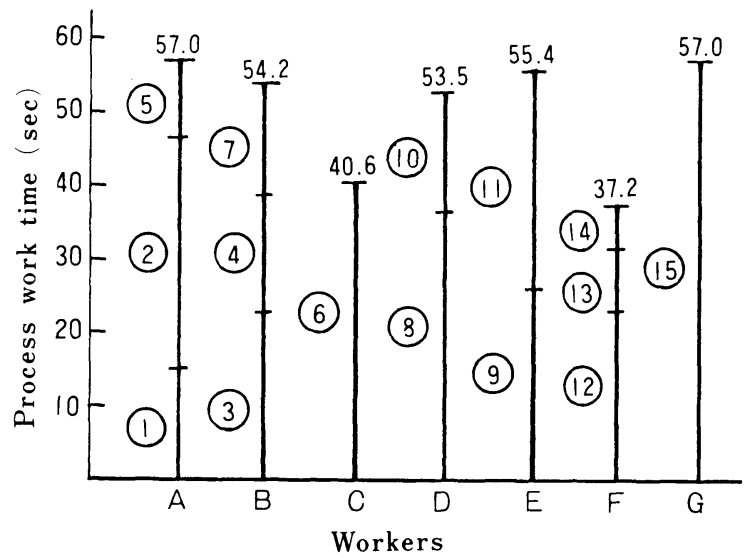

Fig. 6 Process formation by 7 workers.

\subsection{Deciding the minimal cycle time}

In the sewing system, the problem to minimize the cycle time results in making the process formation such as to a minimize the maximum total elemental working time under the technical condition shown in Fig. 4.

Now, the production of 505 clothes/day by eight workers must be increased to 700 clothes/day. The theoretical minimal cycle time : $\iota \iota^{\prime \prime \prime}$, for eight hours a day, is from eq. (9),

$$
\tau_{\text {theo }}=\frac{8 \times 3600}{700}=41.1 \mathrm{sec}
$$

The minimal workstation number is, from eq. (4),

$$
N_{\text {min }}=\left[\frac{T}{\tau_{\text {theo }}}\right]+1=\left[\frac{354.9}{41.1}\right]+1=9
$$

When the process formation for $T=354.9 \mathrm{sec}$ and $N_{\mathrm{min}}=$ 9 is to minimize the total unbalanced time of eq. $3, \Delta$, calculation gives the result shown in Table 3 and Fig. 7, in which the maximum total working time is $41.3 \mathrm{sec}$, and this is the cycle time after formation process. In this case, the production is 697 clothes and is nearly equal to 700 clothes. The production per worker is 69 clothes before and 78 clothes after with $23 \%$ improvement. The idle times of each process and the total idle time when the cycle time is $41.3 \mathrm{sec}$. are shown in VI and VII of Table 3 . The formation efficiency is $E=T / n \tau=354.9 /(9 \times 41.3)=0.95(95 \%)$.

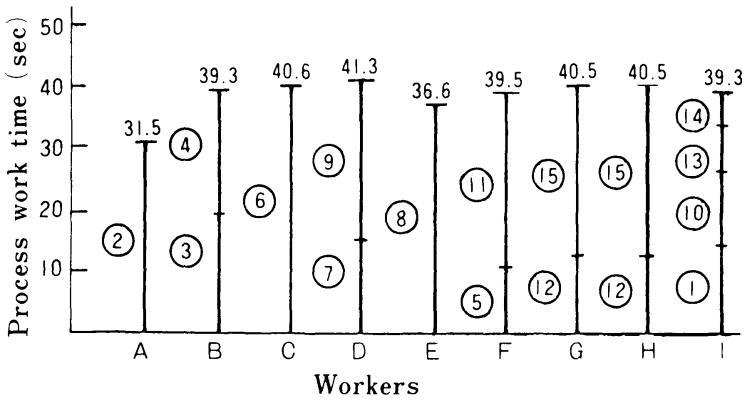

Fig. 7 Process formation by 9 workers.

\section{Considerations}

The concept of the total unbalanced time in the sewing system enabled us to decrease the number of workers and to increase the production. In case of calculating the workstation number, the process formation is done to minimize the total unbalanced time by combining the elemental works under the theoretical possible process number. When the elemental work is scarce, for instance less than 10 , the formation is done in a short time. Secondly, to get the minimal cycle time, we usually increase the workers and decrease the

\begin{tabular}{|c|c|c|c|c|c|c|c|c|c|c|c|}
\hline \multicolumn{2}{|c|}{ Numner of workstations } & \multirow[t]{2}{*}{1} & \multirow{2}{*}{$\frac{2}{3}$} & \multirow[t]{2}{*}{3} & \multirow{2}{*}{$\begin{array}{l}4 \\
7\end{array}$} & \multirow[t]{2}{*}{5} & \multirow[t]{2}{*}{6} & \multirow{2}{*}{$\frac{7}{12}$} & \multirow{2}{*}{$\frac{8}{12}$} & \multicolumn{2}{|c|}{9} \\
\hline (I) & Elemental & & & & & & & & & 1 & 10 \\
\hline & & 2 & & 6 & & 8 & & & & & \\
\hline & work & & 4 & & 9 & & 11 & 15 & 15 & 13 & 14 \\
\hline (II) & $\begin{array}{l}\text { Sum of elemental } \\
\text { work times }(\mathrm{sec})\end{array}$ & 31.5 & 39.3 & 40.6 & 41.3 & 36.6 & 36.6 & 40.5 & 40.5 & & 39.3 \\
\hline (III) & Fixed cycle time (sec) & & & & & 41.1 & & & & & \\
\hline (IV) & Unbalanced time (sec) & 9.6 & 1.8 & 0.5 & -0.2 & 4.5 & 4.5 & 0.6 & 0.6 & & 1.8 \\
\hline (V) & $(\sec )$ & & & & & 24.1 & & & & & \\
\hline (VI) & Idle time (sec) & 9.8 & 2.0 & 0.7 & 0 & 4.7 & 4.7 & 0.8 & 0.8 & & 2.0 \\
\hline (VII) & Total idle time (sec) & & & & & 25.5 & & & & & \\
\hline
\end{tabular}

Table 3 Process with minimized total unbalanced time 
elementary work number in each workstation, as the production quantity is generally given. Such a case that the production is increased at the cost of increasing the workers arises when the production quality is very large and the delivery time is short.

We dealt with the data for eight workers under the assumption that the skill of each worker is the same and each worker can do every elemental work. Even if new incomers join the line, the elemental working time is assumed to be the same as the measured data. Strictly speaking, this is a question. But usually, those workers that have the same skill are joined, and the process planning, is done not to change the elemental works before and after the calculation. So, the assumption may be allowed.

\section{Conclusions}

In the production management of the sewing system, the line balancing is studied from the view points of high production and less workers, and the calculating method of the number of workstations and the cycle time is improved by introducing the concept of unbalanced time. The investigation of utility and usefulness for an actual sewing system of geans-making is as follows :

1. When this calculating method workstation number is applied to the line of eight workers and fifteen elemental works, the same production is obtained by only seven workers.
2. When this calculating method for cycle time is applied to the line of 63 clothes/worker/day $(8 \mathrm{hr}$.), the production is increased to 78 , with the improvement of $24 \%$. These example proove the utility of this study and the high possibility of improvement.

\section{Acknowledgement}

We are grateful to Mr. Morio Mizutani, department manager of Toa-Sen-i Industry Co., Ltd., who kindly supported the sewing experiments.

The work described in this paper was conducted a part of a project sponsored by apparel science promotion of Japanese Ministry of Education. The authors gratefully acknow ledge this support.

\section{References}

[1] S. Honda et al.; Quality and Productivity of Textile Products (in Japanese), pp. 3-35 (1979), Japan Apparel News Co.

[2] J. R. Jackson; Management Science, Vol. 2, No. 3, pp. 261-271, (1956).

[3] K. Hitomi; Production Management Engineering (in Japanese), pp. 129-136 (1978), Korona-sha. 